\title{
Câmaras setoriais no Governo do Estado do Pará
}

Luis Carlos Freitas Rodrigues

\section{Introdução}

Em janeiro de 2007, o Governo do Estado do Pará definiu como modelo de planejamento e gestão a constituição de câmaras setoriais. Essas ficariam responsáveis pela elaboração de propostas, construção e acompanhamento de políticas públicas, dentro de uma dinâmica de interação permanente dos principais atores da administração pública estadual, governadoria, secretarias, órgãos e empresas públicas, fundações e demais instâncias que compõem o quadro do Executivo.

No final de 2006, foram analisadas algumas experiências nacionais, em que a formação de grupos de gestores governamentais seniores de nível decisório atingiu resultados significativos, principalmente comparando-se com os modelos tradicionais de gestão pública ainda em vigor. Essas experiências trouxeram à tona anseios de muitos dirigentes, principalmente governadores, que viam na modernização do planejamento e no acompanhamento sistêmico e 
profissional de políticas públicas a maneira decisiva de organizar a gestão mediante modelos mais eficientes e dinâmicos, se comparados aos modelos formais de administração dos bens e serviços públicos.

A partir de meados dos anos 1990, o Brasil iniciou processo de reconfiguração do seu modelo de gestão. Administração pública foi alvo de intensas reformulações, em suas mais variadas instâncias, com a tônica em um modelo neoliberal, que se traduziu na construção, acelerada, de um padrão que privilegiou o perfil traçado pelos países centrais e organismos financeiros internacionais, em que a eficiência arrecadadora, o contingenciamento de recursos para as áreas sociais e a pouca participação da população nos níveis decisórios marcariam de maneira substantiva tal modelo. $\mathrm{O}$ governo brasileiro, ao seguir esse padrão, optou por métodos já comuns e existentes no receituário dos organismos internacionais (principalmente FMI e Bird), pois passava por um processo de privatização de estatais, controle dos gastos públicos, superávit fiscal e reestruturação da gestão pública.

Em 1995, com a criação do Ministério da Administração e Reforma do Estado, o governo federal criou uma instância que centralizou as operações referentes ao movimento de aproximação do modelo de gestão do país com configurações neoliberalizantes. Dessa forma, a implementação de diversos conceitos que já estavam em uso na administração pública de países centrais tomou forma na gestão pública brasileira, principalmente no âmbito federal.

Um desses novos mecanismos foi a criação de grupos de trabalhos permanentes na forma de assessorias de alto nível técnico, que devem compor o quadro de gestores públicos para subsidiar o gestormáximo em procedimentos e deliberações sobre a condução da gestão em suas diversas áreas. Os gestores seguem um padrão de trabalho em que existe a composição de atividades com perfil tipicamente público e a adaptação de processos originários da iniciativa privada, algo comum na administração pública brasileira desde os anos 1990, com "claro estabelecimento de objetivos e monitoramento de desempenho; poder outorgado à administração superior.” (FERLIE et al, 2000, p. 27).

Deve-se priorizar a gestão de processos de forma que a exigência sobre o gestor público tenha como foco principal a construção de um canal sistêmico, em que os processos possam, de maneira contínua, passar por monitoramentos e padrões de controle e qualidade efetivos. A construção de espaços de deliberação e decisão sobre as políticas públicas compartilhadas ou setorizadas, com a direção de um grupo gestor de alto desempenho, passou a ser um dos objetivos principais de muitos setores governamentais no Brasil, principalmente no âmbito federal e estadual.

A dissolução de antigos modelos e padrões já existentes, principalmente os originados na configuração estatizadora pré-neoliberalismo, desafia a implementação do novo modelo. Nesse processo de transição, a convivência entre o antigo padrão e o novo modelo é uma constante na administração pública brasileira, onde o encaminhamento desse processo tem sido realizado com um conjunto de gestores afeitos ao antigo modelo e um conjunto de novos servidores com conhecimento e know-how do modelo de gestão adaptado da iniciativa privada. Lê-se então o desafio de ordenar as condições de trabalho, planejamento e gestão que são impostas por tal realidade. É muito comum, em um mesmo órgão, a existência de padrões otimizados de administração e modelos típicos da 
administração mecanicista e burocrática de outros tempos. Vale ressaltar que atuar de maneira profissional junto à gestão pública não significa descaracterizar a administração governamental ou torná-la privada.

\section{As câmaras setoriais no setor público}

Um dos modelos que se apresenta como proposta de inovação para esse segmento é a formação das chamadas "câmaras setoriais", que têm como proposta de trabalho a formação de grupos de técnicos e gestores que possam, de maneira compartilhada, debater e definir as questões que envolvem elaboração e execução de políticas públicas em seus diversos parâmetros.

O primeiro ponto de discussão para a composição de câmaras setoriais é a definição do planejamento estratégico do governo ${ }^{1}$, pois é diante desse plano que podem ser idealizadas as tipologias de câmara, a sua dimensão político-gerencial, e também o seu poder decisório dentro do campo governamental que se deseja. Um modelo de câmara tem sempre a anuência da autoridade governamental máxima, que deve conhecer seus mecanismos de trabalho, técnicos-coordenadores e os padrões que cada câmara deve imprimir. Pode-se afirmar que, apesar de um padrão uniforme de atuação, as câmaras têm suas peculiaridades, até mesmo pelo gênero de cada setor onde irão atuar.

O segundo item é a composição dos membros das câmaras. Esses técnicos devem ser escolhidos pelo alto escalão governamental, sendo as câmaras alocadas junto às secretarias que tenham influência em todos os níveis decisórios do governo. A qualificação do corpo técnico será ponto preponderante quando as câmaras começarem a funcionar efetivamente, pois em muitos momentos a tomada de decisão ficará sob a responsabilidade desses gestores governamentais. Isso sempre significa, no mínimo, um embate com ideias contrárias, fazendo-se necessário que uma das principais características desses técnicos seja o poder de persuasão que devem ter para atrair o maior número de gestores e instituições para o plano inicial por eles formatado, ou discutido no âmbito das câmaras. Por isso,

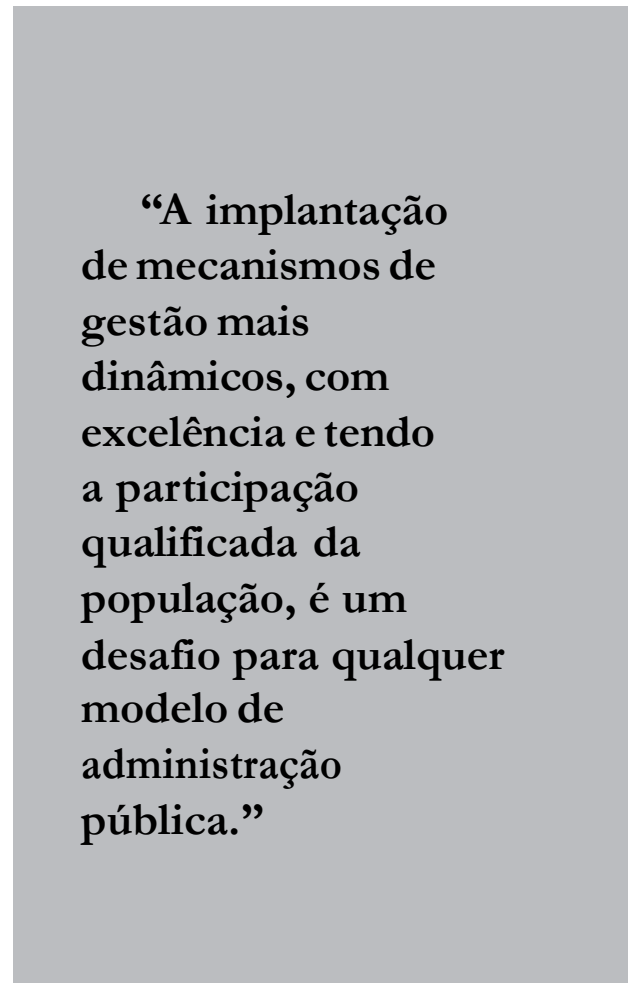

a validação das ideias, métodos, práticas e planos das câmaras deve ter um alto percentual de embasamento técnico, tornando, dessa forma, o processo de planejamento mais qualificado e garantindo assim o seu sucesso.

O terceiro ponto é o embate político que, em maior ou menor grau, faz parte da ambiência onde as câmaras estão inseridas. Nesse aspecto, as relações das 
câmaras com os demais componentes do governo devem sempre priorizar os projetos estabelecidos no momento da composição do planejamento estratégico. É dele que migram os objetivos, os planos e as metas definidas em cada área de abrangência. É muito comum os componentes das câmaras serem partícipes do planejamento, já com a visualização da realidade operacional de cada política pública a ser desenvolvida, bem como a sua viabilidade política. Como, para a quase totalidade do que está sendo planejado, fazse necessário o aval dos demais atores Assembleia Legislativa, Ministério Público etc. -, fomentar a interação com essas instâncias é também tarefa das câmaras.

Esse núcleo estratégico, que são as câmaras, deve organizar as ações de uma periferia operacional que muitas vezes encontram-se em meio difuso de gestão e sem experiência de interação com esse formato, já que a grande maioria dos projetos e programas do Estado agora são multidisciplinares, o que exige equipes multidisciplinares tanto para o planejamento quanto para a execução das ações intersecretariais de políticas públicas. $\mathrm{O}$ modelo tradicional não pode ser visto como um empecilho para a nova forma de articulação proporcionada pelo sistema de câmaras. Ele deve interagir com a nova realidade, com os novos procedimentos, já que a execução das atividades sempre será das secretarias e demais órgãos, o que significa a utilização de processos de gestão já em andamento e aceitos como eficientes para a dinâmica (FERLIE et al, 2000).

Outro expediente comum às câmaras é a avaliação de desempenho dos executores das políticas públicas. Esse processo requer a formatação de modelos e padrões de acompanhamento não muito usuais na iniciativa pública, que tradicionalmente opta pela avaliação quantitativa e finalística; enquanto o processo utilizado pelas câmaras deve percorrer o caminho qualitativo, acompanhando as diversas fases dos projetos e programas, assim como tecendo críticas, elaborando relatórios parciais e final, realizando análise custo-benefício e demais projeções específicas para cada área de atuação do Estado. Ao se dimensionar cada necessidade de acompanhamento e controle, as câmaras tecem, dessa forma, uma rede de informações que, ao ser analisada conjuntamente (intercâmaras), possibilita a montagem de um mapa sobre as políticas públicas implementadas, finalizadas e as que estão em fase de discussão para implementação. É desse mapa que se extraem as informações estratégicas que devem ser encaminhadas aos dirigentes de cada secretaria e/ou órgão para seu respectivo conhecimento, controle e providências.

A caracterização de um padrão de gestão pública de excelência a partir das câmaras deve então dar indicativos de sua funcionalidade, criando referências e intensificando a utilização de sistemas de informação mais dinâmicos que os usualmente utilizados pela gestão pública. No caso do Estado do Pará, um dos principais desafios é a criação de canais de informações técnicas ágeis e seguras, que possam subsidiar os gestores de dados e referenciais com qualidade suficiente para análises mais detalhadas das políticas, desde seu projeto até o seu feedback ${ }^{2}$. Os modelos anteriores eram, na sua maioria, estanques e com um sistema de informação desencontrado; com muita sobreposição, tanto na geração de dados quanto na execução dos projetos, e ainda no acompanhamento das atividades ${ }^{3}$.

A partir dessa premissa as câmaras optam, inicialmente, pela apreensão dos 
dados existentes. Os grupos que compõem cada câmara começam a processar as informações existentes, originadas nas diversas secretarias e órgãos da administração estadual, gerando uma quantidade significativa de informações, dados e análises sobre as diversas áreas que compõem o governo estadual. No Pará, devido a uma política de setorização e à falta de armazenamento de dados estatísticos e históricos, o trabalho exigiu não apenas a reformulação do método, mas a construção conjunta de novos mecanismos de gestão, em que um grupo interdisciplinar de técnicos de diversas áreas teve que estruturar esse padrão junto a um corpo técnico de servidores efetivos, ainda com os mecanismos anteriores de gestão em uso.

As câmaras, organizadas em parâmetros de gestão mais dinâmicos, encontraram a realidade efetiva da gestão pública paraense. Setorização, padronizações em excesso, individualismos da alta gestão, sucateamento dos sistemas de informação, falta de dados confiáveis, irrisória participação da população nos níveis decisórios etc. A inversão dessas defasagens torna-se, após a formação das equipes das câmaras e da consolidação de suas metas e objetivos, passo importante no trabalho desenvolvido.

\section{Implantação das câmaras setoriais no Estado do Pará}

A implantação de mecanismos de gestão mais dinâmicos, com excelência e tendo a participação qualificada da população, é um desafio para qualquer modelo de administração pública. As câmaras devem sempre caminhar nesse sentido e buscar a organização das diversas ferramentas de gestão que possam levar a atingir seus objetivos. Apesar das dificuldades em esquadrinhar todas essas ferramentas, pois para cada segmento são necessários padrões e modelos que seguem a tipologia apropriada a cada setor, tem-se hoje na gestão contemporânea uma gama de referenciais que podem servir, ou ser adaptados, para as necessidades da gestão pública, principalmente se tratando de modelos gerenciais diversos e inter-relacionados.

No Estado do Pará, as câmaras passaram a se utilizar desses referenciais; alguns conseguiram avanços significativos, outros ainda carecem de melhorias e alguns não deram certo, conforme Quadro 1.

As câmaras setoriais no Governo do Pará começam a preconizar uma orientação com referência à transição de um modelo gerencial de administração pública setorizado e burocrático para uma nova realidade organizacional, na qual o papel das grandes mudanças estruturais implementadas, quase de maneira invariável por novos governos, tende a perceber que essas mudanças não podem ser realizadas sem a participação efetiva do corpo técnico existente, além dos demais servidores, que formam a periferia operacional e, conjuntamente, executam as atividades propostas via políticas públicas. "Como os quadros de mudanças intencionais ou mais radicais são mais evidentes, tende-se a considerá-los únicos e a subestimar a importância dos processos de mudança contínuos, que constituem a dinâmica própria de cada organização." (FISCHER apud FLEURY, 2002, p. 147).

Essa tendência tornou-se mais complexa porque as câmaras, no caso paraense, não tiveram tempo para uma melhor análise da situação organizacional e de gestão, quando ocorreu a transição de governo. Algumas câmaras ainda não tinham suas equipes totalmente formadas e organizadas no início do mandato, o que 


\section{Quadro $1^{4}$}

\begin{tabular}{|c|c|c|c|}
\hline $\begin{array}{l}\text { Modelos de Gestão } \\
\text { aplicados pelas } \\
\text { câmaras }\end{array}$ & Histórico & Avanços & Dificuldades \\
\hline Extensão da auditoria. & $\begin{array}{l}\text { As câmaras apoiaram } \\
\text { a revitalização da } \\
\text { Auditoria-Geral do } \\
\text { Estado. }\end{array}$ & $\begin{array}{l}\text { Aumento do número de } \\
\text { auditagem, fortalecimento } \\
\text { da política de controle, com } \\
\text { uma nova visão sobre o } \\
\text { processo de auditoria, } \\
\text { seguindo a tendência de } \\
\text { qualificação no controle. }\end{array}$ & $\begin{array}{l}\text { Construção do } \\
\text { novo modelo de } \\
\text { auditagem. }\end{array}$ \\
\hline $\begin{array}{l}\text { Claro estabelecimento de } \\
\text { objetivos e monitoramento } \\
\text { de desempenho setorizado. }\end{array}$ & $\begin{array}{l}\text { Criação de dinâmicas } \\
\text { de socialização dos } \\
\text { objetivos intercâmaras, } \\
\text { cabendo a cada } \\
\text { coordenador o } \\
\text { monitoramento junto } \\
\text { aos seus } \\
\text { colaboradores, } \\
\text { secretarias e órgãos, } \\
\text { e o repasse de } \\
\text { informações } \\
\text { estratégicas à } \\
\text { governadora, } \\
\text { com notas técnicas } \\
\text { e relatórios. }\end{array}$ & $\begin{array}{l}\text { A socialização das } \\
\text { informações entre os } \\
\text { membros das câmaras } \\
\text { permite maior precisão das } \\
\text { ações, bem como mantém a } \\
\text { governadora constantemente } \\
\text { informada sobre o } \\
\text { andamento das políticas } \\
\text { públicas em sua gestão. }\end{array}$ & $\begin{array}{l}\text { Algumas secretarias } \\
\text { e órgãos ainda } \\
\text { carecem de } \\
\text { maior aproximação } \\
\text { com a sua respectiva } \\
\text { câmara, e até } \\
\text { mesmo precisam } \\
\text { compreender a } \\
\text { função que elas têm } \\
\text { no governo. }\end{array}$ \\
\hline $\begin{array}{l}\text { Criação, em nível local, } \\
\text { de organizações mais } \\
\text { autônomas. }\end{array}$ & $\begin{array}{l}\text { Tem esse objetivo } \\
\text { principalmente por se } \\
\text { tratar de um estado } \\
\text { com as dimensões } \\
\text { do Pará. }\end{array}$ & $\begin{array}{l}\text { Devido ao pouco tempo de } \\
\text { implantação das câmaras, } \\
\text { os avanços ainda são } \\
\text { pequenos neste item. }\end{array}$ & $\begin{array}{l}\text { Longo período } \\
\text { de distanciamento } \\
\text { do nível local em } \\
\text { relação ao poder } \\
\text { central do Estado } \\
\text { do Pará. Abandono } \\
\text { da criação dos } \\
\text { níveis locais de } \\
\text { decisão - físicos e } \\
\text { técnicos - dificultando } \\
\text { a autonomia na } \\
\text { tomada de decisão. }\end{array}$ \\
\hline $\begin{array}{l}\text { Mudança para estruturas } \\
\text { organizacionais mais } \\
\text { horizontalizadas. }\end{array}$ & $\begin{array}{l}\text { Com as ações } \\
\text { intersetoriais das } \\
\text { políticas públicas, a } \\
\text { estrutura } \\
\text { horizontalizada foi a } \\
\text { forma encontrada pelas } \\
\text { câmaras que melhor se } \\
\text { adapta a sua execução e } \\
\text { monitoramento. }\end{array}$ & $\begin{array}{l}\text { Algumas secretarias } \\
\text { começam a romper com a } \\
\text { administração verticalizada } \\
\text { em prol de uma gestão } \\
\text { compartilhada e } \\
\text { descentralizada, } \\
\text { distribuindo melhor suas } \\
\text { tarefas e aumentando a } \\
\text { eficiência. }\end{array}$ & $\begin{array}{l}\text { A hierarquização } \\
\text { de vários setores da } \\
\text { administração } \\
\text { pública paraense } \\
\text { ainda é } \\
\text { significativa, } \\
\text { mesmo em } \\
\text { secretarias em que } \\
\text { esse processo não } \\
\text { deveria mais } \\
\text { existir. A ênfase nos } \\
\text { processos } \\
\text { burocráticos supera } \\
\text { a inovação e a } \\
\text { agilidade } \\
\text { administrativa em } \\
\text { muitos casos. }\end{array}$ \\
\hline
\end{tabular}




\begin{tabular}{|c|c|c|c|}
\hline $\begin{array}{l}\text { Aumento no papel das } \\
\text { formas de organização } \\
\text { em rede. }\end{array}$ & $\begin{array}{l}\text { Condição fundamental } \\
\text { para o funcionamento } \\
\text { das câmaras, visualizado, } \\
\text { desde o início, como } \\
\text { um dos itens mais } \\
\text { importantes na formação } \\
\text { do modelo proposto. }\end{array}$ & $\begin{array}{l}\text { Na ambiência interna, as } \\
\text { câmaras têm funcionado } \\
\text { exatamente como um } \\
\text { sistema em rede. Atuando } \\
\text { conjuntamente e distribuindo } \\
\text { atividades de forma precisa } \\
\text { entre as câmaras e seus } \\
\text { componentes, em que cada } \\
\text { um sabe de suas atribuições, } \\
\text { alimenta a "rede" constante- } \\
\text { mente com o resultado do } \\
\text { seu trabalho. }\end{array}$ & $\begin{array}{l}\text { Ainda não foi possível } \\
\text { conseguir imprimir, de } \\
\text { maneira mais } \\
\text { abrangente, esse ritmo } \\
\text { internamente nas } \\
\text { secretarias, e externa- } \\
\text { mente nas ações } \\
\text { intersecretariais. } \\
\text { Dificuldade com a } \\
\text { capacidade instalada } \\
\text { nas secretarias, o } \\
\text { corporativismo de } \\
\text { muitas categorias } \\
\text { profissionais e o } \\
\text { despreparo dos } \\
\text { gestores indicados } \\
\text { pelo atual governo } \\
\text { estadual. }\end{array}$ \\
\hline $\begin{array}{l}\text { Descentralização com } \\
\text { desempenho julgado com } \\
\text { base nos resultados. }\end{array}$ & $\begin{array}{l}\text { Todas as ações das } \\
\text { câmaras têm sua } \\
\text { avaliação pautada pela } \\
\text { descentralização dos } \\
\text { mecanismos de gestão, } \\
\text { e a avaliação dos } \\
\text { resultados obtidos em } \\
\text { cada um dos processos. }\end{array}$ & $\begin{array}{l}\text { A disseminação desse } \\
\text { padrão tem, cada vez mais, } \\
\text { conquistado espaço nas } \\
\text { secretarias, que estão } \\
\text { ampliando suas ações na } \\
\text { direção de um processo de } \\
\text { descentralização mais } \\
\text { dinâmico e tecnicamente } \\
\text { viável. }\end{array}$ & $\begin{array}{l}\text { As instituições } \\
\text { estaduais ainda não } \\
\text { se apropriaram das } \\
\text { ferramentas de gestão } \\
\text { que levem a esse } \\
\text { objetivo. Muitas } \\
\text { necessitam de uma } \\
\text { reestruturação mais } \\
\text { profunda, inclusive } \\
\text { junto ao seu corpo } \\
\text { técnico. }\end{array}$ \\
\hline $\begin{array}{l}\text { Preocupação com a } \\
\text { qualidade dos serviços. }\end{array}$ & $\begin{array}{l}\text { As câmaras tendem a } \\
\text { aproximar suas ações de } \\
\text { modelos de qualidade e } \\
\text { excelência na prestação } \\
\text { dos serviços. }\end{array}$ & $\begin{array}{l}\text { Aplicação, mesmo } \\
\text { que pouco } \\
\text { sistematizada, dessa } \\
\text { ferramenta junto às } \\
\text { políticas públicas em } \\
\text { andamento ou } \\
\text { planejadas no estado. }\end{array}$ & $\begin{array}{l}\text { As câmaras ainda não } \\
\text { dominam esse } \\
\text { aspecto da gestão, e } \\
\text { ainda carecem de } \\
\text { melhor } \\
\text { aparelhamento para } \\
\text { tal visualização do } \\
\text { processo em si, e } \\
\text { posteriormente para a } \\
\text { sua disseminação junto } \\
\text { aos membros de cada } \\
\text { câmara. }\end{array}$ \\
\hline
\end{tabular}

ocasionou a confrontação de dados, a busca de informações muitas vezes desencontradas, e a falta do conhecimento prévio diante da máquina governamental a ser gerida.

A partir da formação das equipes e do domínio das características de gestão de cada setor, as câmaras começam a delimitar e a esquadrinhar melhor seu raio de ação, sua função dentro do governo, e até a sua missão, esclarecendo inter e intracâmaras mecanismos de procedimentos, controle e avaliação. Assim, o governo inicia um processo de mudança na gestão, cabendo às câmaras a execução do novo plano, em que os critérios de implantação de modificações em organizações complexas devem funcionar como um processo contínuo de construção e reconstrução do significado da organização, com o qual se busca aperfeiçoar sistemas, processos, políticas e práticas que constituem sua gestão (Fisher apud Fleury, 2002). 
Alinhadas a uma política de aumento da participação da população nos níveis decisórios, as câmaras setoriais do Pará buscam, na gestão por excelência, a capacidade de estruturar as políticas públicas do governo do estado, bem como as parcerias com governos federal e municipais, agências internacionais de fomento e o setor produtivo, diante de um quadro em que as palavras 'recuperação e valorização' constituem desafios à construção de nova metodologia de gestão pública, com ferramentas e vontade política caminhando em estreita consonância.

O Quadro 2 apresenta a atual formação das câmaras setoriais de gestão do Governo do Estado do Pará. A composição foi dividida em seis setores, que agrupam as secretarias e demais órgãos da administração direta e indireta do Estado. Os grupos foram alinhados de acordo com objetivos, funções e atividades. As câmaras têm processo dinâmico e contínuo de articulação entre seus componentes. Projetos e programas interdisciplinares são analisados de maneira conjunta entre os atores envolvidos e passam por uma avaliação sistêmica, por meio de simulações ou partindo para análises comparativas com experiências anteriores ou executadas em outros estados - até em outros países -, minimizando o risco das ações e aproximando-se do planejamento estratégico com tais práticas; lembrando que os procedimentos estratégicos, neste caso, referem-se à situação de colaboração e aliança para alcançar os objetivos esperados (Maximiano, 2006).

Essa composição, que permanece até hoje, tem sido amplamente acionada através de tarefas e atividades de curto, médio e longo prazos. As câmaras setoriais foram testadas à exaustão no primeiro ano de governo, pelo que está indicado no
Quadro 1, e também pela falta de capacidade técnica instalada em várias instâncias do Estado que, em um primeiro momento, não conseguiam acompanhar o ritmo imposto pelas câmaras, sendo necessária, em alguns casos extremos, a mudança de gestores e a implantação de mecanismos mais eficientes de gestão, planejamento e controle.

Outro desafio também ocorrido no primeiro ano de governo foi a migração de coordenadores e técnicos das câmaras para ocupação de secretarias e demais postos estratégicos no Estado do Pará. O fenômeno não descaracterizou as câmaras e suas atividades. Porém, toda mudança de equipe, principalmente no início das atividades, causa transtornos como a busca de um novo coordenador de câmara com o perfil desejado para tal cargo. Essa busca leva tempo e pode atrasar alguns mecanismos em andamento, já que a seleção requer todo cuidado para não criar efeito de descontinuidade nos processos encaminhados, bem como garantir a adaptação desse novo gestor à realidade tão singular das câmaras setoriais.

As câmaras têm subsidiado o governo com ações estratégicas para a execução de projetos intersetoriais, criando grupos de trabalho para oportunizar junto às secretarias uma ambiência de interação mais dinâmica e empenhada na formatação de cenários de gestão compartilhada. Essa metodologia necessita de melhor depuração, tanto por parte das câmaras quanto das secretarias, já que a individualidade e o fator político muitas vezes contribuem para a derrocada de alguns procedimentos. Porém, é notório que a grande maioria das ações no primeiro ano de governo só foram adiante após a sua sistematização pelas câmaras, principalmente as que necessitaram de ação conjugada entre duas ou mais secretarias. 


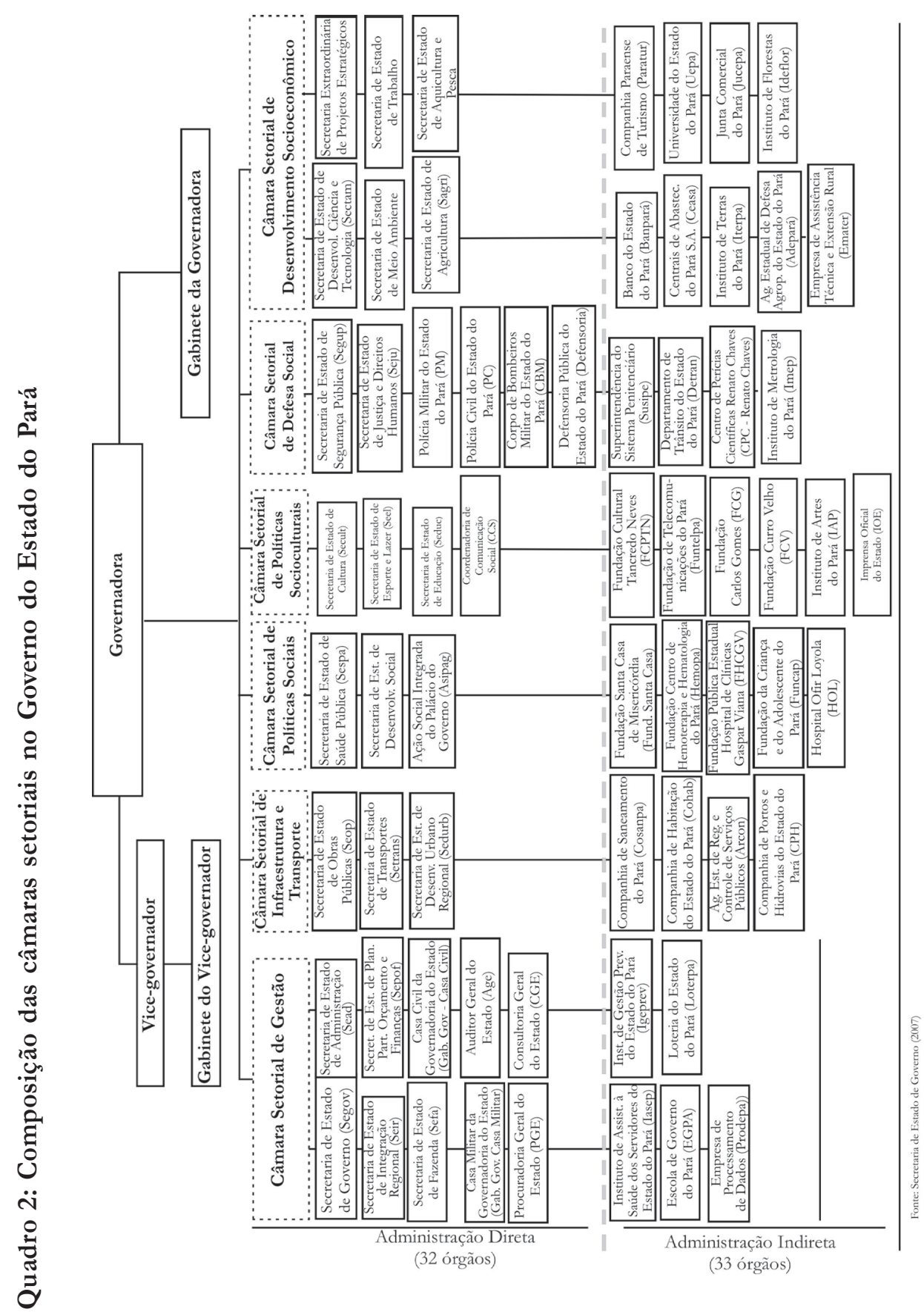


Outro aspecto desse modelo é a adaptabilidade por parte dos gestores, principalmente dos componentes que fazem parte da autogestão de cada secretaria, junto a um modelo de gestão compartilhada. Ainda acostumados a um processo operacional com rotinas internalizadas, os funcionários das instituições governamentais não tiveram tempo suficiente para o amadurecimento da ideia de executar atividades em consonância com as câmaras setoriais, quando necessário. Algumas secretarias ainda insistem em atuar de maneira individualizada no momento em que as ações necessitam da integração ou mesmo do suporte das câmaras. As secretarias têm obtido resultados muito abaixo, se comparado com as que trabalham de maneira compartilhada e com a orientação das câmaras. Ainda não existem estudos detalhados nem índices sobre esse aspecto. Porém, é visível a dificuldade encontrada pelas secretarias mais reticentes em integrar a metodologia das câmaras para avançar em seus objetivos e metas.

Um exemplo foi a necessidade de desenvolver ações de política pública com o governo federal, sendo um caso específico o Programa para Aceleração do Crescimento (PAC) no Pará, que iniciou suas atividades no estado a partir de 2007, após uma ação direta da Câmara Setorial de Infraestrutura e Transporte, que integrou a Secretaria de Urbanismo, a Companhia de Saneamento do Estado do Pará, a Companhia de Habitação, a Secretaria de Governo. De forma conjugada e por meio de uma gestão compartilhada, esses órgãos implantaram um escritório do PAC em Belém e viabilizaram recursos financeiros $\mathrm{e}$ humanos para o andamento de projetos nas áreas de saneamento e habitação, na ordem de R \$ 1 bilhão, sendo uma ação que não ocorria no estado há mais de dez anos.
O convênio para a execução das obras foi assinado em janeiro de 2008.

Esse exemplo mostra como uma mobilização conjunta liderada por uma câmara pode significar o encurtamento de prazos, a vinculação interinstitucional de fato, e a divisão sistemática de direitos e deveres de cada agente estadual envolvido no programa.

\section{Conclusão}

As câmaras setoriais implantadas desde o início de 2007 no Estado do Pará apresentam, após um ano, diversidade de ações e diretrizes que apontam para uma interação constante com os órgãos e secretarias estaduais. Projetos e programas têm sido gerados e executados com o ordenamento das câmaras, sem tirar das secretarias a executabilidade e o planejamento de projetos, programas e rotinas individuais, nem sua independência diante dos objetivos.

O papel que as câmaras vêm exercendo no Pará aponta para a definição clara de opção por um modelo dinâmico e descentralizado de gestão, proveniente de um esforço concentrado dos entes governamentais para o cumprimento de metas e cronogramas. Além disso, oportuniza políticas públicas de maneira intensiva, com a construção de modelos de gestão que possam interagir com as diversas necessidades originadas em cada área governamental.

A construção das câmaras setoriais proporciona o desencadeamento de novos procedimentos de gestão, em que o planejamento, o acompanhamento e a avaliação de políticas públicas ocorrem de forma descentralizada. Câmaras, secretarias e demais órgãos criam cenários e dinâmicas propícias para uma visão sistêmica e compatível com cada necessidade específica, por área. 
O modelo paraense ainda sofre com a falta de preparo de algumas secretarias para o novo ambiente de gestão. Algumas câmaras necessitaram ser redimensionadas, tanto na sua composição funcional quanto em suas diretrizes básicas junto às secretarias. Apesar da característica comum, as câmaras têm aspectos que individualizam o seu comportamento em cada área onde estão inseridas.

O posicionamento do Governo do Pará tem sido o de fortalecimento das câmaras. Porém, secretarias e demais órgãos, em alguns momentos, ainda sentem dificuldades em interpretar a real função das câmaras setoriais. Essa dificuldade, comum no processo de transição de governo com diferentes perfis, torna- se um pouco mais acentuada diante da mudança de metodologia de gestão proposta pela formatação de câmaras setoriais.

A condução da gestão governamental no Pará tem consolidado um perfil de aproximação com ferramentas contemporâneas de administração, em que pesem a diversidade de processos, o encaminhamento e a urgência que caracterizam a tipologia do ser viço público. É um modelo em construção, por isso mesmo sujeito a críticas, alterações e reformas, bem como suscetível a adaptabilidades, com a incorporação de algumas premissas regionais ou de tipologia local.

(Artigo recebido em fevereiro de 2008. Versão final em junho de 2009)

\section{Notas}

1 "O planejamento estratégico objetiva ser um processo contínuo e sistemático de tomada de decisões em que os planos são permanentemente revistos conforme as circunstâncias vão evoluindo, e não segundo um calendário pré-estabelecido.” (SANTOS, 2006).

2 "O ciclo de feedback traz de volta para o sistema uma parte da energia, das informações ou dos resultados que ele produziu” (Maximiano, 2006, p. 313).

3 "Todo sistema é dinâmico e tem processos que interligam os componentes e transformam os elementos de entrada em resultados" (Maximiano, 2006, p. 310).

4 Elaboração do autor, sendo a primeira coluna baseada em Ferlie et al, cap1, 2000.

\section{Referências bibliográficas}

Cunha, Giane Soares da. Avaliação de Politicas e Programas Governamentais: tendências recentes e experiências no Brasil . George Washington University, 2006.

Ferlie, Ewan; Asburner, Lynn; Fitzgerald, Louise; e Pettigrew, Andrew. A nova administração pública em ação. Editora UNB, ENAP, Brasília/DF, 2000.

Fleury, Maria Tereza Leme (Org.) As Pessoas na Organiz̧ação. Editora Gente, SP/SP. 2002. 
Führer, Maximilianus Cláudio Américo e FüHrer, Maximiano Roberto Ernesto. Resumo de Direito Administrativo, $7^{\circ}$ Edição, Coleção Resumos, Malheiros Editores, 2000, São Paulo/SP.

Johnson, Bruce Baner; SAes, Flávio Azevedo Marques de; Teixeira, Hélio Janny ; e Wright, James Terence Coulter. Serviços Públicos no Brasil: Mudanças e Perspectivas. Editora Edgard Blücher ltda, São Paulo/SP, 1998.

Maximiano, Antônio César Amaru . Teoria Geral da Administração: da revolução urbana à revolução digital. Ed. Atlas, SP/SP, 6 Edição, 2006.

Ramos, Dora Maria de Oliveira. Terceirização na Administração Pública. Ed. LTR, São Paulo/SP, 2001.

Rua, Maria das Graças. A avaliação no Ciclo de Gestão Pública (2006). Disponível em: www.enap.gov.br

SAntos, Clezio Saldanha dos. Introdução à Gestão Pública. Ed. Saraiva, São Paulo, 2006. Descentralização e poder local: a experiência das subprefeituras no município de SP. Finatec/ ED. Hucitec, SP/SP, 2004. 


\section{Resumo - Resumen - Abstract}

\section{Câmaras setoriais no Governo do Estado do Pará}

\section{Luis Carlos Freitas Rodrigues}

O artigo apresenta o início da implantação das câmaras setoriais no Governo do Estado do Pará, introduzindo um novo desenho para a gestão das políticas públicas no estado. A pesquisa foi realizada por meio de análise documental junto a diversas instâncias do governo paraense, tendo sido o autor participante da implantação e da coordenação da Câmara Setorial de Gestão até 2007. Primeiramente, faz-se uma análise sobre os novos modelos de gestão pública no Brasil e a dissolução dos antigos padrões. Em seguida, apresenta-se a proposta de câmaras setoriais, seus métodos e conceitos, partindo para avanços e desafios impostos pela implementação do novo modelo, concluise com uma análise sobre o futuro do modelo na gestão pública estadual, bem como a aproximação com ferramentas contemporâneas da administração, interagindo com as diversas áreas do governo estadual.

Palavras-chave: câmaras setoriais, gestão pública, planejamento.

\section{Las cámaras sectoriales en el Gobierno del Estado del Pará}

\section{Luis Carlos Freitas Rodrigues}

El artículo presenta el comienzo de la implantación de las cámaras sectoriales en el Gobierno del Estado del Pará, introduciendo un nuevo modelo para la administración de las políticas públicas en el mencionado estado. La investigación fue realizada mediante análisis documental en diversos organismos e instancias del gobierno, siendo autor y responsable por la implantación y coordinación de las cámaras sectoriales de gestión hasta 2007. Inicialmente se hace un análisis en relación con los nuevos modelos de la administración pública en Brasil y la disolución de los paradigmas antiguos. Seguidamente se presenta la propuesta de las cámaras sectoriales, sus métodos y conceptos, partiendo posteriormente para los adelantos y los desafíos impuestos por la implementación del nuevo modelo. Para finalizar, se realizará un análisis en relación con el futuro del modelo en la administración pública estadual, asi también con la proximidad de éste con las herramientas contemporáneas de la administración, integrándose con las diversas áreas del gobierno estadual.

Palabras clave: cámaras sectoriales, administración pública, planificación.

\section{Sector chambers in Pará State \\ Luis Carlos Freitas Rodrigues}

This paper presents the implementation of Sector Chambers within Pará State Government. It introduces a new structure for public policies management at that State. This research was carried out through primary data analysis within several sectors of Pará State Government, due to the author's experience in the creation of the Management Sector Chambers. First, an analysis about new models of public management in Brazil and the replacement of old patterns is presented, followed by the presentation of Sector Chambers proposal, its methods and concepts. In the sequence, the challenges and improvements of the introduction of a new model are discussed. The article is then concluded by an analysis about the future of state public management, and the use of administration contemporary tools in the diverse public sectors of Pará State.

Keywords: sector chambers, public management, planning. 
Luis Carlos Freitas Rodrigues

Graduado em Administração, mestre em Planejamento Urbano e Regional pelo IPPUR/UFRJ, professor da Área de Ciências Sociais Aplicadas do Centro Universitário do Pará (Cesupa), diretor Administrativo e Financeiro da Secretaria de Estado de Comunicação do Pará.

Contato: luiscarlos@cesupa.br 